\title{
Male partner influence on family planning and contraceptive use: perspectives from community members and healthcare providers in KwaZulu-Natal, South Africa
}

Yolandie Kriel ${ }^{1,2^{*}}$ (D), Cecilia Milford ${ }^{1}$, Joanna Cordero ${ }^{4}$, Fatima Suleman ${ }^{3}$, Mags Beksinska', Petrus Steyn ${ }^{4}$ and Jennifer Ann Smit ${ }^{1}$

\begin{abstract}
Background: South Africa faces numerous reproductive challenges that include high rates of unplanned and adolescent pregnancies. The uptake and utilization of family planning services and modern contraception methods depend on numerous factors. The male partner plays a key role in reproductive health but data on this topic are outdated or have a predominant HIV prevention focus. The purpose of this paper is to explore the influence of male partners on family planning and contraceptive (FP/C) uptake and use within the contemporary South African setting, and to identify further areas of exploration.

Methods: This qualitative study was conducted in a community and healthcare provision setting in the eThekwini District in KwaZulu-Natal province, South Africa. Data were collected from twelve community-based focus group discussions ( $n=103)$, two healthcare providers focus group discussions $(n=16)$, and eight key informant individual in-depth interviews. Following a constructionist paradigm and using the health utilization behaviour model, data were analysed using thematic analysis, allowing a robust and holistic exploration of the data.

Results: The data from this study revealed the complex and evolving role that male partners play in FP/C uptake and use within this setting. Key themes from the data elucidated the dual nature of male involvement in FP/C use. Culturally influenced gender dynamics and adequate understanding of FP/C information were highlighted as key factors that influenced male attitudes and perceptions about contraceptive use, whether positively or negatively. Male opposition was attributed to limited understanding; misunderstandings about side-effects; male dominance in relationships; and physical abuse. These factors contributed to covert or discontinued use by female partners. Pathways identified through which male partners positively influenced FP/C uptake and access include: social support, adequate information, and shared responsibility.

Conclusions: Understanding the role that male partners play in FP/C uptake and use is important in preventing unintended pregnancies and improving family planning policy and service delivery programmes. By identifying the barriers that male partners present, appropriate strategies can be implemented. Equally important is identifying how male partners facilitate and promote adherence and use, and how these positive strategies can be incorporated into policy to improve the uptake and use of FP/C.
\end{abstract}

Keywords: Contraception, Family planning, South Africa, Male partners, Influencers, Barriers, Facilitators

\footnotetext{
* Correspondence: ykriel@mru.ac.za

${ }^{1}$ MatCH Research Unit (Maternal, Adolescent and Child Health Research Unit),

Department of Obstetrics and Gynaecology, Faculty of Health Science,

University of the Witwatersrand, Durban, South Africa

${ }^{2}$ School of Public Health and Nursing, College of Health Science, University

of KwaZulu-Natal, Durban, South Africa

Full list of author information is available at the end of the article
}

(c) The Author(s). 2019 Open Access This article is distributed under the terms of the Creative Commons Attribution 4.0 International License (http://creativecommons.org/licenses/by/4.0/), which permits unrestricted use, distribution, and reproduction in any medium, provided you give appropriate credit to the original author(s) and the source, provide a link to the Creative Commons license, and indicate if changes were made. The Creative Commons Public Domain Dedication waiver (http://creativecommons.org/publicdomain/zero/1.0/) applies to the data made available in this article, unless otherwise stated. 


\section{Plain English summary}

South Africa faces numerous reproductive health challenges including high unmet need among unmarried women, high rates of unplanned pregnancies, and high rates of adolescent pregnancies. Male partners play a key role in reproductive health, but more information is needed to gain a better understanding about the influence of male partners on the uptake of family planning and contraceptive $(\mathrm{FP} / \mathrm{C})$ use within the contemporary South African setting. Numerous pathways were identified that showed how the male partner influences $\mathrm{FP} / \mathrm{C}$ uptake and use. Male partners can influence FP/C use negatively by obstructing contraceptive use that result in either discontinuation or covert use. Both discontinued and covert use increases the female partner's risk of having an unplanned or unintended pregnancy. The data also showed that male partners can improve FP/C uptake and use by providing social support, supplying FP/ $\mathrm{C}$ information and sharing the responsibility of using $\mathrm{FP} / \mathrm{C}$ correctly and consistently.

Key factors that require attention are the quality of FP/ $\mathrm{C}$ information given to men, the inclusion of men in $\mathrm{FP} / \mathrm{C}$ programmes, and the effect of the decline in marriage rates in this setting on $\mathrm{FP} / \mathrm{C}$ uptake and use. Using a qualitative and community-based approach contextualised the findings and identified further areas for research.

\section{Background}

Unmet need for contraception remains a global challenge and in 2014, it wa estimated that more than 225 million women in the developing world were unable to access and use family planning or contraception (FP/C) [1]. While globally there has been an increase in contraceptive prevalence and decrease in unmet need since 1970, the Sub-Saharan Africa region continues to have the lowest contraceptive prevalence at $24 \%$ and highest level of unmet need at 25\% [2].

South Africa faces key reproductive health challenges that are entrenched in socio-political and cultural factors. The overall unmet need is $18 \%$, while the contraceptive prevalence rate (CPR) for married women is 54 and $64 \%$ for unmarried women [3]. Currently there is no data available on male unmet need in South Africa, however the couple year protection rate (CYPR) is estimated to be $70.2 \%$ [4]. SA's CPR and unmet need rates have stagnated over the past two decades $[5,6]$. This stagnation is a cause for concern as modern $\mathrm{FP} / \mathrm{C}$ methods and services are freely and widely available through the SA public healthcare system [7].

Along with the stagnated CPR and high unmet need, other key reproductive health challenges include high rates of unplanned pregnancies, high rates of adolescent pregnancies, and a large generalised HIV epidemic where young women are predominantly affected $[3,8,9]$. Unplanned pregnancies tend to be highest among young, unmarried women who are HIV positive $[9,10]$. Child bearing also starts at a very young age for women in South Africa, with the average age of first conception being below 21 years of age, with those women being unmarried [11]. Unplanned pregnancies amongst this young age group, between 15 and 25 years, are particularly worrisome as studies have demonstrated that there is a potential link between HIV acquisition, antiretroviral treatment initiation and unplanned pregnancies amongst young women $[9,12,13]$.

Numerous factors influence $\mathrm{FP} / \mathrm{C}$ use including interpersonal relationships [2]. Inter-personal relationships include family, community members, religious leaders, healthcare providers and intimate partners $[6,14]$. The most significant inter-personal relationship in $\mathrm{FP} / \mathrm{C}$ use is the intimate male partner relationship and the role of gender dynamics $[15,16]$. The male partner's role in FP/ $\mathrm{C}$ use is complex, and ranges from macro-level sociocultural, economic, political and gendered factors, to more micro everyday-level factors [2, 14, 17].

Even though nearly $40 \%$ of households in South Africa are headed by women, men continue to hold considerable power over women $[7,11]$. This is mainly attributed to the culturally elevated status that men have over women and men being more economically empowered [11, 14]. Male dominance is reinforced through political and economic mechanisms that limit women's access to financial independence and therefore their ability to access and use FP/ C methods and services $[2,14,17-19]$. In the South African context, gender inequality, past political policies, and patriarchal cultural norms drive female disempowerment, which negatively influences $\mathrm{FP} / \mathrm{C}$ use $[7,16,20]$.

Culture guides behaviour and is a macro-structural factor that influences reproductive behaviour [21-23]. Patriarchal views on gendered roles are socially constructed and reinforced within various cultural settings and result in women lacking autonomy to make their own decisions about using FP/C methods [24]. These patriarchal cultural views give men power to decide how many children a couple should have [25].

Recent studies in the sub-Saharan region have identified a variety of micro-level factors through which the male partner negatively influences $\mathrm{FP} / \mathrm{C}$ uptake and use. These factors include male partners having negative personal beliefs about $\mathrm{FP} / \mathrm{C}$; limited access to $\mathrm{FP} / \mathrm{C}$ information; myths and misconceptions; perceived side effects including decreased sexual pleasure; marital status; poor economic status; religious influences; limited male contraceptive choice; suspicion of female partner infidelity; and male preference for larger families as reasons to oppose FP/C use [6, 14, 16, 20, 26-28]. Furthermore, negative interactions with healthcare providers (HCPs) is another important factor that influence male involvement in $\mathrm{FP} / \mathrm{C}$ use [29]. 
Most FP/C studies are conducted from the female perspective and focus on women who are clinic attendees, to capture the FP/C experience. This reflects the female dominated view that is often captured in $\mathrm{FP} / \mathrm{C}$ studies and results in the male voice being silenced $[16,28]$. There is also an overbearing assumption that men are always barriers, uninterested or by-standers in $\mathrm{FP} / \mathrm{C}$ use, [30,31] and that their influence results in discontinuation of $\mathrm{FP} / \mathrm{C}$ use.

Studies have shown that good communication between couples positively influence $\mathrm{FP} / \mathrm{C}$ use, and can reduce the risk of misconceptions [6]. Good communication also results in joint-decision making about $\mathrm{FP} / \mathrm{C}$ use, which has been linked to improved adherence [27]. Supportive male partner attitudes and positive views of $\mathrm{FP} / \mathrm{C}$ services play an important role in promoting $\mathrm{FP} / \mathrm{C}$ use [15]. It has also been reported that men exposed to $\mathrm{FP} / \mathrm{C}$ educational programmes were four times more likely to support $\mathrm{FP} / \mathrm{C}$ use [32].

Much of the South African work focussing primarily on $\mathrm{FP} / \mathrm{C}$ is outdated, due to the shift in focus to HIV/ AIDS treatment and prevention, and the integration of care [33]. Furthermore, most recent studies are conducted outside the South African setting, focussing on areas where unmet need for $\mathrm{FP} / \mathrm{C}$ is comparatively high. While these findings are enlightening, they are in some instances more relevant within their own context. It is therefore important to examine context specific behaviours when studying a complex topic such as FP/C use, as these practices are steeped in local cultural understandings, beliefs and norms [14].

The influence that male partners has on $\mathrm{FP} / \mathrm{C}$ use varies across regions and settings. Clarity is needed to understand the holistic role of male partners in $\mathrm{FP} / \mathrm{C}$ use within specific contexts, especially the contemporary South African setting [17, 31, 34]. In this article, we explore the role that male partners play in $\mathrm{FP} / \mathrm{C}$ uptake and use from a community and healthcare provider-based perspective.

\section{Context}

The eThekwini District, where the data for this study was collected, is the third largest in South Africa, with a population size of slightly below three and a half million people, the dominant language spoken is IsiZulu [35]. The CYPR for the district is $66.1 \%$ for $2016 / 2017$, which is just above the national target of 50\% [4]. The province has seen the largest decrease in CYPR of 8 percentage points between 2014/2015 and 2016/2017 [4]. KwaZulu-Natal has the third lowest CPR for any method at 53.1\% in South Africa.

In terms of demographics, currently, $23.9 \%$ are married, $66 \%$ have never married, $5.6 \%$ are living together, $2.9 \%$ are widowed, $1 \%$ is divorced and $0.5 \%$ separated [35]. The low marriage rates in the district reflect the current state of marriage in South Africa that is in decline and at a national low [36, 37]. KwaZulu-Natal also has the highest number of people living with HIV/AIDS in the country [38].
Two large areas were chosen within the district that represent a mixture of rural, peri-urban and urban areas. Area 1 (defined as the rural area for purposes of this study) presents a combination of rural/peri-urban economic mixture with approximately $60.8 \%$ of the houses being formal, while Area 2 represents the urban/periurban setting with $65.1 \%$ of houses being formal. Both areas are predominantly populated by Black South Africans (99.5\%), who speak IsiZulu [35].

\section{Methods}

This study was conducted as part of formative work to inform the development of an intervention that aimed to increase met need for $\mathrm{FP} / \mathrm{C}$ through community and healthcare provider ( $\mathrm{HCP}$ ) participation, in South Africa, Kenya and Zambia (the UPTAKE Project). In this paper, we report on findings from the South African site on the role that men play in $\mathrm{FP} / \mathrm{C}$ uptake and use.

A qualitative methodology was used to gather data from the two areas described above within the eThekwini district of KwaZulu-Natal. In-depth interviews (IDIs) were conducted with key informants (KIs) and focus group discussions (FGDs) were held with community members and HCPs between June and December 2015. A key aspect of this study was the inclusion of community members, who may or may not have been users of $\mathrm{FP} / \mathrm{C}$, rather than clients accessing services at healthcare facilities. The rationale for this approach was to obtain a contemporary perspective on $\mathrm{FP} / \mathrm{C}$ services and method use by community members. This information could then inform $\mathrm{FP} / \mathrm{C}$ services to improve $\mathrm{FP} / \mathrm{C}$ delivery to those who are at need.

In-depth interviews (IDIs) were conducted with key informants (KIs), who ranged from educators to community care givers, traditional healers, and programme managers for sexual and reproductive health programs. Eight KIs were selected purposively or via snowball sampling, based on expertise, and participated in an IDI. It was estimated that between eight and ten KI IDIs would be required to reach data saturation, which was achieved with the eight KIs interviewed.

Healthcare providers from eight healthcare facilities in the district were invited to participate. Two FGDs were held with HCPs who were directly providing FP/C services or who were based in service delivery points which may promote or inform women about $\mathrm{FP} / \mathrm{C}$ options. Healthcare providers from eight healthcare facilities in the district were invited to participate. In total sixteen HCPs participated in the FGDs. HCP group $1(n=8)$ consisted of higher ranked professionals, such as professional nurses and operational managers. HCP group 2 $(n=8)$ consisted of counsellors, nursing assistants and enrolled nurses. The HCP groups were structured in such a way as to promote open discussion. 
Finally, twelve FGDs were conducted with male and female community members $(N=103)$. The groups were composed according to several factors: urban/peri-urban vs rural/peri-urban, age, sex, parity and marital/relationship status. Local community advisory boards (CAB) assisted with identifying potentially eligible participants and purposive sampling was used to recruit community members according to FGD categories and eligibility criteria. (See Table 1 for participant breakdown.)

The FGDs were conducted by research assistants who were matched by gender and language to the participants to facilitate rapport. The research assistants were all trained in conducting FGDs and all had previous experience of using qualitative methodology to collect data. HCP FGDs were conducted by the study project manager who is fluent in both English and isiZulu. The FGDs were

Table 1 Breakdown of participants per FGD and IDI participants

\begin{tabular}{|c|c|}
\hline FGDs conducted & No. of participants ( $n$ ) \\
\hline 1. Females, urban, teenagers (aged 15-19 years) & 9 \\
\hline $\begin{array}{l}\text { 2. Females, rural/peri-urban, teenagers (aged } \\
15-19 \text { years) }\end{array}$ & 10 \\
\hline $\begin{array}{l}\text { 3. Females, urban, young adults (aged 20-34 } \\
\text { years) }\end{array}$ & 8 \\
\hline $\begin{array}{l}\text { 4. Females, rural/peri-urban, young adults } \\
\text { (aged } 20 \text { - } 34 \text { years) }\end{array}$ & 10 \\
\hline 5. Females, urban, adults (aged 35-49 years) & 8 \\
\hline $\begin{array}{l}\text { 6. Females, rural/peri-urban, adults (aged } \\
35-49 \text { years) }\end{array}$ & 7 \\
\hline 7. Males, teenagers (aged 15-19 years) & 10 \\
\hline 8. Males, young adults (aged 20-34 years) & 8 \\
\hline 9. Males, adults (aged 35-49 years) & 7 \\
\hline $\begin{array}{l}\text { 10. Females who are unmarried, single } \\
\text { (20-34 years) }\end{array}$ & 8 \\
\hline $\begin{array}{l}\text { 11. Females who are married/in a relationship } \\
>1 \text {-year ( } 20-34 \text { years) }\end{array}$ & 10 \\
\hline $\begin{array}{l}\text { 12. Females with no children (who are not } \\
\text { infertile) (18-49years) }\end{array}$ & 8 \\
\hline Total community participants & 103 \\
\hline $\begin{array}{l}\text { 13. HCP from local health facilities (including } \\
\text { management, professional nurses): Group } 1\end{array}$ & 8 \\
\hline $\begin{array}{l}\text { 14. HCP from local health facilities (including } \\
\text { enrolled nurses, counsellors, and other } \\
\text { operational staff): Group } 2\end{array}$ & 8 \\
\hline Total HCP participants & 16 \\
\hline \multicolumn{2}{|l|}{ Key stakeholders } \\
\hline 1. Education & 1 \\
\hline 2. Community Care Givers & 2 \\
\hline 3. Traditional Healer & 1 \\
\hline $\begin{array}{l}\text { 4. Programme Managers working in } \\
\text { sexual and reproductive health (SRH) }\end{array}$ & 4 \\
\hline Total key stakeholders & 8 \\
\hline
\end{tabular}

conducted in either isiZulu and/or English to ensure that participants were able to express their views without a language barrier. FGDs lasted between one to two hours.

The IDIs were conducted by either a research assistant, study coordinator, or senior researcher to facilitate rapport with the participants. FGDs were conducted at community-based facilities. Key stakeholders were interviewed at locations convenient for them, that ranged from the research site's offices to the participant's home.

All the FGDs and IDIs that were conducted in isiZulu were translated and back-translated by research assistants who are fluent in both languages. These transcripts were then reviewed and checked for accuracy by the researchers. Any ambiguity in the translations were discussed and clarified with the respective research assistant and interviewer to ensure the accuracy of the translations. At the end of the project, the results were shared with the community members, and there was a high degree of agreement from the community members with the results presented. This further contributed to the validity and accuracy of the data.

Interview guides contained key theme specific questions that were tailored for each category type of participant, including: the female FGDs, male FGDs, HCP FGDs, and key stakeholder IDIs. Adolescent participants were asked the same questions as per their respective gender to the adult participants. Similar key theme questions were asked that inquired about understandings of family planning; knowledge, attitudes and practices; key barriers and enablers to family planning access; perceptions and definitions of quality of care; and the role of community participation in family planning and contraceptive services. Specifically, participants were asked who the most important people are in supporting women and girls in choosing and using $\mathrm{FP} / \mathrm{C}$. This resulted in the emergence of the male partner and themes described in this paper.

The purpose of the approach discussed above was to gain the perspectives of each category/type of participant. Obtaining various perspectives is congruent with employing a social constructionist approach in analysing the data, where opinions are valued equally. This was an important stance to adopt considering the varied categories of participants that were involved in this study.

Voluntary informed consent was obtained from all adult participants aged 18 years and older. For minors, below the age of 18 years, consent was obtained from their parents and/or legal guardians and assent from the minors to participate in the study. Permission to audio record all FGDs and IDIs was included in the informed consent forms. In addition to the audio recordings, detailed field notes were taken. During FGDs the interviewer was assisted by a note-taker who was fluent in the language the FGD was conducted in. IDI interviewers took their own notes while conducting the interview. 


\section{Data analysis}

The IDIs and FGDs were audio recorded and transcribed verbatim. The transcripts of the FGDs and IDIs conducted in isiZulu were translated into English. Demographic data were collected and descriptively analysed.

Qualitative data analysis was done using thematic content analysis, following a social constructionist approach. Social constructionism provided a theoretical framework through which to explain and understand the interpretation of cultural constructs in family planning and contraceptive use $[39,40]$. These cultural constructs provide mechanisms of control that govern individual's behaviour within a given society, which is pertinent to the study of sexual and reproductive health [23]. In addition, Andersen's [41-43] Health Utilization Model and Penchansky and Thomas's [44] definition of the concept of access to healthcare further aided in the development of the a priori code list.

A master code book was developed amongst the researchers in all three countries in which the larger study was conducted. This team approach allowed for rich discussion about the meaning of concepts and codes, further establishing the validity and appropriateness of the code list. Independent coders double coded a subset of the data to increase reliability of the data. The constant comparison method was used to further explore the data and develop additional themes [45]. NVivo (version 10, QSR International) was used as the computer assisted qualitative data analysis software that facilitate coding and analysis of the data.

A priori themes were identified using the Health Utilization Model, the Bruce-Jain framework for Quality of Care, and Penchansky and Thomas's definition of access to healthcare [41, 44, 46]. Inductive and emergent themes were also elucidated in the data of which the male partner's role in FP/C uptake and use emerged. The use of social constructionism as a theoretical framework allowed for the exploration of opinions about FP/C use by a variety of different perspectives. This stance allowed for a more robust and richer understanding to emerge about the role that male partner's play in $\mathrm{FP} / \mathrm{C}$ use in this setting.

Themes were derived from the initial coding, and later grouped into categories. The constant comparison method as described by Ryan and Bernard (2003) [45] was used to identify emergent themes in the data. An indepth discussion on the overall methodology used in this project is described elsewhere [47].

\section{Results}

\section{Demographic results}

Table 2 shows the demographic details of the community members, and Table 3 shows HCP and key informant demographics. Community males had a mean age of 23.8 years, compared to females who had a mean age of 26.4 years. Notably, only two female participants were married. Of the male and female participants who reported pregnancies, 32 and $66.6 \%$ respectively, $87.5 \%$ of males and $86.5 \%$ of females reported that their pregnancies were unplanned. For current contraceptive use, 12\% of males and $19.2 \%$ of females reported not using any methods at the time of data collection.

\section{Thematic results}

Figure 1 below demonstrates the various FP/C methods that community participants discussed. Community members had a good range of information about available products. Figure 1 also demonstrates the differences and similarities in $\mathrm{FP} / \mathrm{C}$ method discussion between men and women. Male condoms were equally discussed between men and women, followed by discussions about hormonal injections. Perhaps the most interesting aspect to note of Fig. 1 is that men discussed emergency contraception significantly more than women. This issue will be addressed further in a separate paper.

\section{The obstructive male partner}

Knowledge about the various FP/C methods available in the community was high among community members (Fig. 1). Even so, some young male adult participants reported that they required more detailed information to improve their understanding of $\mathrm{FP} / \mathrm{C}$ methods:

\section{F: "[O] kay, what information does he [the male partner] need about these methods?}

P1: "It's important to know how it works. Concerning my health, if there will be any effect and how is going to help me?"

P4: "How safe is it [for] me, and my partner [?] ... It is right for my partner while it gives me a problem. If my partner has been using this thing, [ ... ] I shouldn't have a problem afterwards."

P8: "Yes, I want to know a lot about them because I don't know much about it."

\section{[Young Adult Males, FGD]}

HCPs pointed out that the feminisation of FP/C services and education contributed to men being misinformed:

"Because now we are not concentrating on males we only give them condoms. So it ends up being like, feminine, yet it's not supposed to be, it's a family thing it's [for] everybody."

[Female KI, HCP, IDI] 
Table 2 Demographic data for male and female community participants

\begin{tabular}{|c|c|c|c|c|}
\hline \multirow[t]{2}{*}{ Demographic Characteristics } & \multicolumn{2}{|c|}{ Community males $(n=25)$} & \multicolumn{2}{|c|}{ Community females $(n=78)$} \\
\hline & Percent \% & $\mathrm{N}$ & Percent \% & N \\
\hline Age & 23.8 years $[15-40]$ & & 26.4 years [15-49] & \\
\hline Female & - & & $75.0(n=78)$ & 103 \\
\hline Male & 24.27 & 103 & - & \\
\hline \multicolumn{5}{|l|}{ Education } \\
\hline Below completed secondary school level & 84.0 & 21 & 48.7 & 38 \\
\hline Above completed secondary school level & 16.0 & 4 & 51.3 & 40 \\
\hline \multicolumn{5}{|l|}{ Relationship status } \\
\hline Regular partner, $>1 \mathrm{yr}$., not living together & 28.0 & 7 & 62.0 & 48 \\
\hline Regular partner, < 1 yr., not living together & 28.0 & 7 & 21.0 & 16 \\
\hline Regular partner, $>1$ yr., living together & 8.0 & 2 & 3.0 & 2 \\
\hline Married & 0 & 0 & 3.0 & 2 \\
\hline Divorced & 0 & 0 & 1.0 & 1 \\
\hline Casual partner & 16.0 & 4 & 0 & 0 \\
\hline No current partner & 4.0 & 1 & 10.0 & 8 \\
\hline Multiple partners & 16.0 & 4 & 0 & 0 \\
\hline \multicolumn{5}{|l|}{ Sexual and reproductive history } \\
\hline Positive Pregnancy & 32.0 & 8 & 66.6 & 52 \\
\hline Unplanned pregnancies & 87.5 & 7 & 86.5 & 45 \\
\hline Planned pregnancies & 12.5 & 1 & 15.3 & 8 \\
\hline \multicolumn{5}{|l|}{ Current contraceptive use } \\
\hline None & 12.0 & 3 & 19.2 & 15 \\
\hline Male condoms & 68.0 & 17 & 60.2 & 47 \\
\hline 3 monthly injection & 24.0 & 6 & 24.0 & 19 \\
\hline Pill & 8.0 & 2 & 2.5 & 2 \\
\hline Implant & 4.0 & 1 & 8.9 & 8 \\
\hline
\end{tabular}

Table 3 Demographic data for the healthcare providers and key informants

\begin{tabular}{|c|c|c|c|c|c|c|}
\hline \multirow[t]{2}{*}{ Demographic } & \multicolumn{2}{|l|}{ HCP group $1(n=8)$} & \multicolumn{2}{|l|}{ HCP group $2(n=8)$} & \multicolumn{2}{|l|}{ Key informants $(n=8)$} \\
\hline & Percent \% & N & & N & Percent \% & N \\
\hline Age & 39.2 years [28-56] & & 37.6 years [26-47] & & 51.2 years [25-66] & \\
\hline Female & 75.0 & 6 & 100.0 & 8 & 87.5 & 7 \\
\hline Male & 25.0 & 2 & 0 & 0 & 12.5 & 1 \\
\hline \multicolumn{7}{|l|}{ Education } \\
\hline $\begin{array}{l}\text { Below completed secondary } \\
\text { school level }\end{array}$ & 0 & 0 & 0 & 0 & 25.0 & 2 \\
\hline $\begin{array}{l}\text { Above completed secondary } \\
\text { school level }\end{array}$ & 0 & 0 & 0 & 0 & 12.5 & 1 \\
\hline Tertiary incomplete & 0 & 0 & 37.5 & 3 & 0 & 0 \\
\hline Tertiary complete & 100 & 8 & 62.5 & 5 & 62.5 & 5 \\
\hline Years of experience in current position & 4.9 years & & 6.4 years & & 10 years & \\
\hline
\end{tabular}




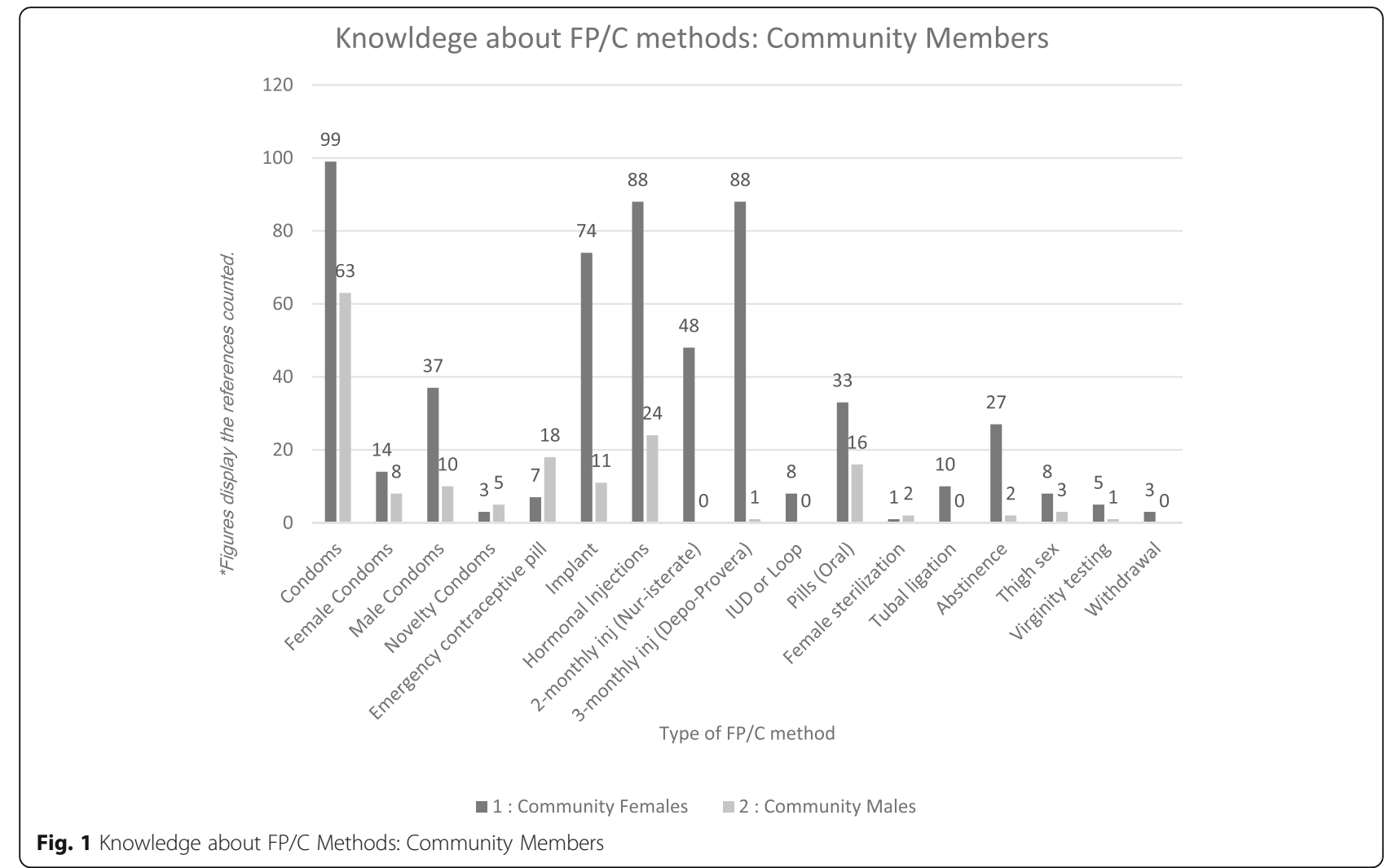

Some female participants argued that a lack of information and understanding could result in incorrect assumptions about side-effects and negative attitudes towards FP/ $\mathrm{C}$ by male partners, as well as misconceptions and myths about the effects of using FP/C methods:

"Males are not the same, there are males who will hear females talking among themselves saying someone who takes injection becomes wet, he takes that [information, and when] you tell him that you [use] the injection he says you [are] wet [... ] what does he know, what does he know?”

\section{[Young female adult, Rural, FGD]}

A married female participant added to the view the men do not understand how $\mathrm{FP} / \mathrm{C}$ methods work:

"He believes that if you are on injection you are killing the baby because he does not have babies [... ] It means that you go to the clinic to kill [the] sperm that he produces."

\section{[Married Females, FGD]}

Side effects, whether perceived or real, were identified as key contributors to male opposition to $\mathrm{FP} / \mathrm{C}$ use. Although numerous side effects are associated with $\mathrm{FP} / \mathrm{C}$ use, increased vaginal wetness and decreased male sexual pleasure were the two most significant side effects described by men.

One young male adult participant explained how the use of the hormonal injection and the associated increased vaginal wetness was unacceptable for men:

"Ay and you find that the queen [female partner] ... you find that your queen is loose like jelly [all laughing] and that is caused by the injection. That is not right my brother that thing [all laughing and one says: it does not treat her right]. The injection is wrong."

\section{[Young Adult Males, FGD]}

The view that men over exaggerated vaginal wetness was shared widely across the female participant groups, as one female participant explains:

"I agree with [other participant], most males can see that you are on injection. There is nothing that they think about besides water retention that you are always wet. Even if you are not he will say you are wet."

[Married Females, FGD] 
Decreased male sexual pleasure was another side effect attributed to male opposition to $\mathrm{FP} / \mathrm{C}$ use:

"SS] ometimes we men don't really allow women to use ... these family planning services [...] Because sometimes they make us uncomfortable and they make sex, less enjoyable."

\section{[Male KI, Edu, IDI]}

This was particularly in reference to male condoms, as one young adult male participant pointed out:

"[U] nprotected sex is nice [others laughing] and this is something that makes men happy. Ay, unprotected sex is nice. With a condom, you just feel the plastic [..]"

\section{[Young Adult Males, FGD]}

Men could also influence FP/C use negatively by accusing their female partners of salacious behaviours, as one adult female participant explained:

"[Y] ou will speak to the person and tell him you want to use injection and he will start to have stories saying since you are on injection it means you are sleeping around. You must not tell him that you are on injection you must just go and have your injection and keep quiet."

[Urban Adult Females, FGD].

Another reported factor was the difference in discordant fertility desires between partners. One female participant reported that men generally want more children which could result in men being resistant to $\mathrm{FP} / \mathrm{C}$ use:

"I'm saying sometimes you discuss [FP use] with your partner, but other times you don't discuss with him because sometimes males enjoy [it] that they have many children [...] Males don't care if they had penetrated [you] and you fell pregnant. He doesn't have stress you see."

\section{[Rural Young Adult Females, FGD]}

Desire for boy-children by men contributed to additional male resistance to $\mathrm{FP} / \mathrm{C}$ use as on adult male explains:" $[A]$ nother thing is that we want our families to grow. You sometimes find that you are the only boy in your family, all the others are girls. You will find that sometimes you are getting girls too, your wish is that 'I wish to get a boy' [... ]"

\section{[Adult Males, FGD]}

Cultural constructs about gendered roles, responsibilities and dynamics within this local setting is a contributing factor in male opposition to $\mathrm{FP} / \mathrm{C}$ use. Discussions about marriage and the payment of a bride wealth (iLobola) highlighted this theme of gender dynamics and ownership. The role of paying iLobola was explained by one male participant:

"Before, my brother, you would not have sex with a girl if you are not married or without having paid lobola you see. [... ] As time went by things changed and they never paid attention to that. But if you go to other places [traditional Zululand] you see, where [the Zulu] culture [is] still really followed, you find that thing happening where a guy does not have sex with a girl without having paid lobola [...] If you had sex with that girl without having paid lobola it is a must my brother that he pays for her because she has become his wife."

\section{[Young Adult Males, FGD]}

Despite the changing practices surrounding marriage and the payment of bride wealth, the fact that women continue to belong to their male partners was highlighted by one key stakeholder HCP:

"Well, definitely we need to have more male involvement because [... ] I said women are reallythey are almost like their properties, and I hate to say that [...]. They are the properties of the men."

[Female KI, HCP, IDI]

A female participant described how men own women's bodies and control reproduction through the payment of bride wealth:

"No, you not supposed to [use contraception], you have to wait for your hubby [husband], your hubby has to get it [vagina] as it is. Because they say he paid for it [vagina], isn't it?"

\section{[Females without Children, FGD]}

This ownership could result in discontinuation of FP/ $\mathrm{C}$ use, as a married female participant explained:

"I cannot use a condom with a woman that I am going to marry' [imitating a male partner with a deep voice], and they have many stories."

[Married Females, FGD]

Physical abuse and concomitant contraceptive sabotage were additional ways in which men reportedly 
prevented female partners from using $\mathrm{FP} / \mathrm{C}$, as one adult female participant explained:

"[T] here are people who do not do anything [use FP/C methods] and when you advise her that times are difficult she says "my partner will fight with me and my religion does not allow me to use family planning and injection. Now I am forced [not to use FP/C] because my partner is going to hit me, he is going to fight with me".

\section{[Urban Adult Females, FGD]}

Related to the physical abuse, were reported instances where male partners damaged $\mathrm{FP} / \mathrm{C}$ methods, to compromise their effectiveness. A KI HCP described how some male partners break the Implant in their female partner's arms:

"[W] ith the Implanon [... ] the boyfriend [s] and the husband [s], for some reasons they were finding itfeeling it- [...] And they were actually saying 'go and take it out,' they were actually breaking it in the woman's arm [... ] But with the Implanon I guess they knew that it was set underneath the skin so then they were going and actually feeling for it and they found it and then it became an issue."

\section{[KI, HCP, IDI]}

A female participant explained how men sometimes punctured male condoms to establish power in relationships:

"Look you hold a male condom [ ... ] at the beginning and put it on, he pretends as if he is holding it, yet he [tears] it you see [... ] It has a hole and since it has a hole this boy wants a baby..."

\section{[Rural Adult Females, FGD]}

A major theme that emerged from this data was covert use of $\mathrm{FP} / \mathrm{C}$ methods by female partners because of male partner opposition. Covert use was widely discussed by all the participants in the study, suggesting that this behaviour is perhaps more prevalent in this setting than elsewhere. It was often linked to a lack of communication between men and women.

"At first you will think that you are respecting him by discussing with him, then it's just that boys don't like the issue of injections. Then you see that it's better to just go the clinic without telling him, but most of the boys really don't like this thing that's why we are hiding it from them when we [are] doing it."

\section{[Rural Adolescent Females, FGD]}

A HCP added to the covert use conversation by describing that women hide their clinic cards from their male partners:

"I think it is a problem that a man does not want his partner to do family planning, they say sister I hide my card because he does not want me to do family planning because he thinks I am having many partners."

[HCP Group 2, FGD]

A behaviour that was confirmed by a female participant who reported using FP/C methods:

"I go for injection come back and hide my card, on my date I go and come back there at the clinic, I don't tell him."

[Females without Children, FGD]

One adult female participant explained how male misinformation, side effects and covert use link together in this setting:

"I am going to agree with them because it is right if you start by going for injection without telling him because he never feels anything but once you tell him he is going to talk about water that he never felt before [yes, laughing]. Maybe you have been having sex for a year while on injection. Now that you have told him about injection. If you want to see how much a man loves you tell him about injection issue [laughing] he will tell you that you are cold, or you have water [somebody laughing] but you have been having sex without him feeling it"

[Urban Adult Females, FGD]

\section{The supportive male partner}

As the quotes from the female participants below point out, not all male partners are the same. Some male partners were described as sources of information and being supportive and encouraging of $\mathrm{FP} / \mathrm{C}$ use.

P1: "No there is no such a thing [in response to previous comment that men obstruct FP/C use], mine doesn't have a problem, he even reminds me that 'no your date [is] like this and that, do you still remember', he doesn't have a problem about water [being wet] [...], no he is right [ ...] For me it was him who took me to the clinic". 
P4: "[ ... ], mine he takes me to the clinic, he accompanies me to go for injection if he is around. He likes that I take injection, he can't see himself without me taking injection."

\section{[Rural Young Adult Females, FGD]}

A quote from one young male adult further supports this view:

"Plan the family by first going to the clinic to get counselling with your partner. You go with your partner to counselling session [s] [ ...] and they will explain further about that thing."

\section{[Young Adult Males, FGD]}

Numerous female participants reported that their male partners were often their source of $\mathrm{FP} / \mathrm{C}$ information:

"I have a great relationship with my boyfriend. He is the one who told me that 'no baby, have you heard about this 3 years [implant] that is now available?' I said 'what 3 years now?', he said 'we have to get protected even though we are using the first one [male condoms] let's use this one as well' [... ]"

[Urban Young Adult Females, FGD]

Some female participants remarked that there were few sources of support in their communities for $\mathrm{FP} / \mathrm{C}$ use where they lived, and that their male partners often provided this support:

"Most of the time you get it [support] from males, your partner than women. Women, other women, when you say that you [are] on contraceptives others criticise you [...] And [you] find that they criticise you. Friends criticise you, not saying it to you, talking to others saying you [are] on injection, so and so. You see, they criticise you. [F: So, there is no support in the community?] It is not there in the community."

[Females without Children, FGD]

Male partners also play a role in reminding women to take their FP/C methods, as one female from the married FGD group described:

"I used them [Pill] for 6 years and was reminding myself with Generations [local television series]. The nice thing is my partner used to call and remind me, [ ... J Because he knew that I was using pills, when I visit him he will ask if I brought them and if I did not we will go back and fetch them [all laughing] he used to remind me and it was nice because we used to remind each other.

\section{[Married Females, FGD]}

Another female participant added to this: II was told by my boyfriend and even now he reminds me, he asks me that, 'have you gone for injection?', because we now have a lot of kids"

[Urban Young Adult Females, FGD]

This support resulted in improved access to FP/C services for women, as one young adult female explained:

"My partner asked me if I did go for family planning on this day, I said 'oh I did not go you know, I forgot'. We went with him the following day."

\section{[Rural Young Adult Females, FGD]}

One female participant explained that such behaviour showed that these male partners shared the responsibility of family planning.

P: "For me it was him who took me to the clinic [all laughing]".

I: "What did he say you are going to do?"

P: "He said I must go take injection to prevent getting another child, we are still young. I said okay, he is wise he got brains."

\section{[Rural Young Adult Females, FGD]}

Sharing the responsibility of using $\mathrm{FP} / \mathrm{C}$ was a key facilitating factor in $\mathrm{FP} / \mathrm{C}$ use, as described in the quotes above and below. A male participant shared this view of the importance of shared responsibility:

"There is something that recently happened, and I liked it, it made me happy. There is a guy I am friends with, [...] he asked one female we were hanging out with to help accompany him to go buy the morning after pills. You see us as males if, we cannot just leave things to them [females] saying that they must do certain things, you too if you know that there is a certain mistake that you made, that courage you give yourself that you see at least you ask because that means the female was going to go, but he is the one who stood up [and said] that because we did this let me go,[... ]. All of us should not just leave things [FP/ 
$C$ use] to women as if they are the ones one-way [get pregnant alone], it is important for us males to think as well."

\section{[Adult Males, FGD]}

\section{Discussion}

The uptake and utilization of FP/C methods and services is key to improving unmet need and decreasing unintended or unplanned pregnancies. In this paper the role of men in FP/C uptake and use was explored within the urban/peri-urban and rural/peri-urban setting in the eThekwini district of KwaZulu-Natal from a community and $\mathrm{HCP}$ perspective.

Use of chronic or long-term medical interventions such as FP/C methods fluctuate on a continuum of use, resulting in variation of use patterns [43]. The findings from this study showed that the influence of the male partner can result in varied degrees of $\mathrm{FP} / \mathrm{C}$ use. Three predominant outcomes on use were reported namely: discontinuation, covert, and improved $\mathrm{FP} / \mathrm{C}$ uptake and use. Contextualisation of findings and awareness of the various macro-structural forces behind male influence on $\mathrm{FP} / \mathrm{C}$ use is important for increasing the uptake and continued use of $\mathrm{FP} / \mathrm{C}$.

The use of FP/C methods within marriage continues to be a focal point of policy and research within the subSaharan setting. However, unlike other countries in the Sub-Saharan region, South Africa is experiencing a decline in marriage rates with KwaZulu-Natal, where this data was collected, having some of the lowest marriage rates in the Sub-Saharan region [37]. In this study, no male participants reported being married (or had ever been married), and only $3 \%$ of female participants reported being married. The decline in marriage rates has implications for $\mathrm{FP} / \mathrm{C}$ use monitoring, interventions and programs. The CPR for unmarried women in South Africa decreased from $68 \%$ in 1998 to $64 \%$ in 2016, and unintended pregnancies are strongly associated with single or divorced people $[3,10]$.

Furthermore, the changes in this fundamental cultural practice has implications for the gender dynamics in relationships. Male participants in this study mentioned how guiding cultural practices involving reproduction are changing. These changes have resulted in men and women renegotiating reproductive behaviour, especially with reported behaviours such as covert $\mathrm{FP} / \mathrm{C}$ use and male partner abdication of childcare responsibilities. Further research is needed to explore the importance and influence that the change in this fundamental cultural practice may have on the uptake and use of FP/C.

Another key finding from this data was the high rates of unplanned pregnancies reported. Most of the community female and male participants reported that their pregnancies were unplanned, despite having knowledge and access to $\mathrm{FP} / \mathrm{C}$ services and methods. This finding is in keeping with findings from other studies that investigated unplanned pregnancies $[9,13]$. The findings from this study sheds some insight into reasons for non-FP/C use that could result in unplanned pregnancies. In particular the role of the male partner as a contributing factor to non-use of FP/C was explored.

\section{Discontinuation of FP/C use}

Most of the negative factors that result in barriers to use overlap in their influence and extent in which they result in $\mathrm{FP} / \mathrm{C}$ discontinuation. Some of the opposing factors resulted in covert, or interrupted use, whereas others led to more permanent discontinuation of $\mathrm{FP} / \mathrm{C}$ use. Factors linked to discontinuation included limited understanding about FP/C methods, side-effects (real or perceived), gender power dynamics, physical abuse, and $\mathrm{FP} / \mathrm{C}$ sabotage.

Gender power dynamics continue to play a crucial role in the use of $\mathrm{FP} / \mathrm{C}$ methods and services, as demonstrated by this study and others $[8,16,30,48]$. Power imbalance was reported more in the marriage setting, where men assumed ownership over female fertility, but the responsibility of raising children belonged to women. In addition to this, discordant fertility desires were also reported with men preferring more children than women. In this context of commodified fertility and reproduction, female partners were subjected to male partner demands and expectations for children. These findings were not unique to this study and was previously reported $[8,28,49]$.

Accounts where female participants and HCPs described physical abuse and fear of the male partner were described as reasons to permanently discontinue $\mathrm{FP} / \mathrm{C}$ use. Female participants described how women may not initiate $\mathrm{FP} / \mathrm{C}$ use or discontinue use out of fear that their male partners will physically abuse them. This fear is not unfounded since physical abuse is prevalent in this setting where $21 \%$ of ever partnered women had experienced abuse by their partners [3].

$\mathrm{FP} / \mathrm{C}$ sabotage was considered another form of abuse reported by all the participants that resulted in discontinued use. HCPs reported instances where male partners would feel for the hormonal Implant and break it in their female partner's arm. Community participants described how men and boys intentionally break or damage male condoms to prevent $\mathrm{FP} / \mathrm{C}$ use. These reports link male opposition to discontinued method use through physical abuse and is a serious concern for $\mathrm{FP} /$ $\mathrm{C}$ uptake and use, which has been noted elsewhere [50].

\section{Covert and interrupted FP/C use}

An important finding from this data was that negative male partner influence did not always result in total discontinuation of $\mathrm{FP} / \mathrm{C}$ use, but also resulted in modified behaviour by female partners, who continued using FP/ 
$\mathrm{C}$ without their male partner's knowledge. Findings from this study revealed that in this setting, covert use may be a common practice amongst female partners and was widely encouraged by female participants and healthcare providers. The extent of covert $\mathrm{FP} / \mathrm{C}$ use remains largely unknown as this data is not routinely collected $[51,52]$. Other studies from the sub-Saharan region found that covert use was not widely practiced $[2,27]$.

Female participants and HCPs reported that covert use was a means for women to control their own $\mathrm{FP} / \mathrm{C}$ choices without the permission or knowledge of their male partners. Despite the seemingly positive influence of this, covert use should be treated with caution as it can result in inconsistent or discontinued use [53]. The fact that women use FP/C covertly in this setting suggests that they have limited negotiating power within their relationships, highlighting their vulnerability.

Providing adequate, accurate and contextually acceptable information is crucial to improving men's attitudes and understanding towards FP/C use. Despite the 2016 SADHS reporting that most people of reproductive age in SA has some $\mathrm{FP} / \mathrm{C}$ information, the data from this study showed that the current provision of $\mathrm{FP} / \mathrm{C}$ information is inadequate [3]. Most male participants lacked a clear understanding about FP/C methods, their mechanism of action and related side-effects. This resulted in misconceptions and myths about side-effects and the reported concern that $\mathrm{FP} / \mathrm{C}$ methods could harm male partners. HCPs explained that the lack of male understanding can be attributed to the feminisation of $\mathrm{FP} / \mathrm{C}$ programmes, where the focus remains on women. According to female participants these misunderstandings resulted in misconceptions and myths related to $\mathrm{FP} / \mathrm{C}$ use, such as female partner infidelity and excessive vaginal wetness.

Side-effects remain a widely reported barrier to $\mathrm{FP} / \mathrm{C}$ use, in this study and others [26]. Male participants described side-effects as a key reason why they do not like or encourage FP/C use. Common side-effects reported by male partners include decreased male sexual pleasure, reduced libido, abnormal menstrual bleeding, and increased vaginal lubrication or wetness. Side-effects can be linked to inadequate information, cultural constructs about reproductive behaviour, male sexual entitlement, and gender power inequality $[6,20,54]$. Resistance to $\mathrm{FP} / \mathrm{C}$ use by male partners are also reported in other studies $[27,29,54,55]$.

Male and female participants reported that increased vaginal wetness, whether real or perceived, was a reason for male partners to discourage $\mathrm{FP} / \mathrm{C}$ use. However, male and female participants had differing views about whether increased vaginal wetness due to $\mathrm{FP} / \mathrm{C}$ use was an actual problem. Female participants felt that men constructed and exacerbated reports of vaginal wetness to encourage discontinuation of $\mathrm{FP} / \mathrm{C}$ use. Male participants reported it as a real concern for them as it decreased their sexual pleasure. Increased vaginal wetness has been reported previously within the South African context before and it is linked to discontinued FP/C use [54, 56, 57].

Decreased male sexual pleasure was another reported barrier to $\mathrm{FP} / \mathrm{C}$ use. Male condom use reportedly decreased male sexual pleasure the most, followed by increased vaginal wetness from hormonal $\mathrm{FP} / \mathrm{C}$ methods (especially the injection). The 2016 SADHS results show that $58 \%$ of women and $65 \%$ of men use male condoms inadequately during high risk sexual practices [3]. The importance of decreased male sexual pleasure on $\mathrm{FP} / \mathrm{C}$ use, especially male condoms, requires further exploration, and is reported in other studies in this setting $[55,58]$.

\section{Improved access, uptake and adherence to $\mathrm{FP} / \mathrm{C}$ use}

Much has been written about the opposing influence that men can have on FP/C use. Less is known about the supportive role and influence that men can have on $\mathrm{FP} /$ use. This study highlighted that male support for FP/C can help female users to overcome barriers to using FP/ $\mathrm{C}$ by facilitating access, encouraging uptake, and improving adherence to $\mathrm{FP} / \mathrm{C}$ methods.

\section{Improved access}

In this study, male and female participants reported that males accompanied their female partners to their local clinics to obtain their $\mathrm{FP} / \mathrm{C}$ methods. This differs from other studies where male accompaniments to $\mathrm{FP} / \mathrm{C}$ facilities are ridiculed and $\mathrm{FP} / \mathrm{C}$ is considered only a female domain [28]. Men are generally economically more empowered which enables them to overcome access barriers such as transport costs or healthcare related fees [7]. By accompanying their female partners, they provide financial support to improve access to $\mathrm{FP} / \mathrm{C}$ services $[28,53]$.

Male partners also provided social support for women to access $\mathrm{FP} / \mathrm{C}$ services. Community related stigma can negatively impact on $\mathrm{FP} / \mathrm{C}$ use, especially if unmarried or adolescent women are accessing $\mathrm{FP} / \mathrm{C}$ services within their immediate community. Female participants reported that little support for $\mathrm{FP} / \mathrm{C}$ use exists in local communities and this negatively impacts on them seeking $\mathrm{FP} / \mathrm{C}$ services and methods. In this sense, the male partner accompanying women to clinics can mitigate against community related stigma.

\section{Encouraging uptake of FP/C}

Female participants reported that in certain cases their male partners suggested and initiated the use of $\mathrm{FP} / \mathrm{C}$ methods. This point highlights the need for men to be included in $\mathrm{FP} / \mathrm{C}$ services and programmes [53, 59]. Men have limited FP/C methods available to them and rely on their female partners to use $\mathrm{FP} / \mathrm{C}$ methods to prevent unplanned pregnancies. Although this may be 
viewed as a limiting factor, it may result in men encouraging female partners to use $\mathrm{FP} / \mathrm{C}$ methods to meet their own needs [59].

The encouragement of FP/C use by men was positively viewed by male and female participants and reflects the recognition by men that cultural and patriarchal practices and attitudes are changing. Cultural change can happen slowly and over many years [23], but if those changes have a positive outcome, then the effects can be tremendous. More culturally focused FP/C programming can greatly assist in constructing new ways in which men and women engage about $\mathrm{FP} / \mathrm{C}$ use.

Male participants pointed out how their perceptions and behaviour regarding $\mathrm{FP} / \mathrm{C}$ use is changing. This may be linked to changes in marriage practices in this setting. According to these men, traditional cultural practices are still strictly observed in more rural areas, whereas is less constrained in peri-urban and urban settings. Contemporary men and women in this setting are negotiating and constructing new roles that they occupy within this cultural context, whereby women take ownership of their reproductive health, and men adapt their behaviour to encourage $\mathrm{FP} / \mathrm{C}$ use.

\section{Improved adherence}

Improved adherence to $\mathrm{FP} / \mathrm{C}$ is probably one of the key positive influencing factors that men can have on $\mathrm{FP} / \mathrm{C}$ use which was reported by female participants. Forgetfulness is a key barrier to continued adherence to any long term chronic treatment. Social support is especially important to ensure that adherence remains adequate and is sustained, especially when negative side-effects can threaten continued use. As demonstrated by this data, men can and do play a key role in improving adherence by reminding their female partners to take FP/C methods, and to attend their scheduled visits at the clinic.

\section{Limitations}

While we deem the methodology, sampling size, and strategies used in this study as adequate, some limitations should be noted. Commonly in qualitative studies limited sample size and generalizability of the findings are critiqued [60]. The aim of qualitative research is in depth and description, and not necessarily breadth [61, 62]. Therefore, we should apply caution in generalizing the findings. The data from this study has shown how important contextualisation is when exploring $\mathrm{FP} / \mathrm{C}$ use. Sometimes not being able to return to the field to follow up on findings, places a limit to the depth of exploration of themes, but returning into the field has cost and time implications. One way to compensate for this limitation is to sample from a variety of participants within a community [63]. Variation sampling was achieved in this study where a variety of participants ranging from community members to healthcare providers were interviewed to obtain a robust exploration to the study question.

\section{Conclusion and recommendations}

In this paper we have shown how men influence the uptake, use and discontinuation of FP/C methods and services in the contemporary South African setting. The focus was on how men influence $\mathrm{FP} / \mathrm{C}$ use as either a barrier or facilitator. These two opposing views provide insight into the complex role that the male partner plays in SRH in general in the South African setting. The preconceived and often perpetuated notion that men are always barriers to $\mathrm{FP} / \mathrm{C}$ use in this setting is challenged by the findings presented in this paper.

Socially constructed gender dynamics continue to play a key role in FP/C uptake and use. Changes in cultural practices linked to gender dynamics has resulted in men and women renegotiating the $\mathrm{FP} / \mathrm{C}$ use space. This was seen in the discussions about covert $\mathrm{FP} / \mathrm{C}$ use, the decline in marriage, and the influence of side effects on sexual pleasure. These findings, and especially the decline in marriage, needs further exploration in the context of FP/C uptake and use.

The other key factor that was highlighted and needs to be further explored is providing accurate, contextual and culturally acceptable information to men to engage them positively into $\mathrm{FP} / \mathrm{C}$ care. While men had good levels of information about $\mathrm{FP} / \mathrm{C}$ products, they lacked a clear understanding about how these products work and their related side effects. There is a need to reconsider the manner in which $\mathrm{FP} / \mathrm{C}$ information is delivered to men to improve their understanding and active participation in $\mathrm{FP} / \mathrm{C}$ uptake and use.

The findings from this paper have implications for national policy and public health $\mathrm{FP} / \mathrm{C}$ programmes. In particular, it was highlighted that although the current family planning policy acknowledges that men should be more included in reproductive health, they are largely excluded in reality. Little guidance is provided in the current $\mathrm{FP} / \mathrm{C}$ policy as to how male involvement can be improved. The findings from this study can be useful in exploring and developing strategies that can improve male partner involvement in $\mathrm{FP} / \mathrm{C}$ use.

Of importance is the need to provide sufficient information and counselling to men and to build on the positive strategies through which men can support and promote $\mathrm{FP} / \mathrm{C}$ use as described in this paper. It is crucial for $\mathrm{FP} / \mathrm{C}$ services to be more inclusive of the male partner interaction. A key strategy as highlighted by the data in this paper is to promote discussions between female and male partners about $\mathrm{FP} / \mathrm{C}$ use and pregnancy intentions that will be empowering for both the partners.

While numerous studies have outlined high rates of unplanned pregnancies, few explore the reasons behind 
non-use of $\mathrm{FP} / \mathrm{C}$ that result in unplanned pregnancy. The findings from this study focused on one particular factor, namely the male partner.

Finally, this paper has shown the importance and usefulness of a community approach when investigating sexual and reproductive health. The involvement of men has added a unique and much needed perspective on FP/C uptake and use in the South African setting. Using a community-based approach to inform the development of $\mathrm{FP} / \mathrm{C}$ research and interventions could be a possible solution to develop improved $\mathrm{FP} / \mathrm{C}$ programmes and services. The community-based approach followed in this study highlighted the potential effectives of engaging men.

\section{Abbreviations}

CPR: Contraceptive prevalence rate; CYPR: Couple Year Protection Rate; FGD: Focus Group Discussion; FP/C: Family planning and contraception; HCP: Healthcare Provider; HIV: Human Immunodeficiency Virus; IDI: In-depth Individual Interviews; Kl: Key Informant/stakeholder; SA: South Africa

\section{Acknowledgments}

The authors would like to thank everyone involved in the larger study project who assisted with data collection. We would also like to thank all the participants who gave their valuable time to participate in this research project. YK would like to thank Dr. Tamaryn Crankshaw form the Health Economics and HIV/AIDS Research Division at the University of KwaZuluNatal for her early input into the initial draft of this manuscript.

\section{Authors' statement}

The authors alone are responsible for the views expressed in the article and they do not necessarily represent the views, decisions or policies of the institutions with which they are affiliated.

\section{Authors' informations}

Ms. Yolandie Kriel", RN M.H.Sc, ykriel@mru.ac.za is a Researcher at the Maternal, Adolescent and Child Health Research Unit (MRU), Department of Obstetrics and Gynaecology, Faculty of Health Science, University of the Witwatersrand, Durban, South Africa. Ms. Cecilia Milford, MSocSci, cmilford@mru.ac.za is a Senior Researcher at the Maternal, Adolescent and Child Health Research Unit (MRU), Department of Obstetrics and Gynaecology, Faculty of Health Science, University of the Witwatersrand, Durban, South Africa. Ms. Joanna Paula Cordero, MA, corderoj@who.int is a consultant at the World Health Organisation (WHO). Prof. Fatima Suleman, PhD, Sulemanf@ukzn.ac.za is Professor in the Discipline of Pharmaceutical Sciences, School of Health Sciences, College of Health Sciences, University of KwaZulu-Natal, South Africa. Dr. Mags Beksinska, PhD, mbeksinska@mru.ac.za is Deputy Executive Director at the Maternal, Adolescent and Child Health Research Unit (MRU), Department of Obstetrics and Gynaecology, Faculty of Health Science, University of the Witwatersrand, Durban, South Africa. Dr. Petrus S Steyn, MD, MPhill, steynp@who.int is a Scientist at the World Health Organisation. Dr. Jennifer Ann Smit, PhD, jsmit@mru.ac.za is the Executive Director at the Maternal, Adolescent and Child Health Research Unit (MRU), Department of Obstetrics and Gynaecology, Faculty of Health Science, University of the Witwatersrand, Durban, South Africa.

* Lead and corresponding author.

\section{Authors' contributions}

The overall study was conceptualised and designed by the WHO team (PS, JC) and country principal investigators (JS). YK and CM coordinated the collection of the data, conducted interviews, did the coding and analysis of data, and wrote the full study report. YK conceptualised and wrote this manuscript. CM, JS, PS, JC, FS and MB contributed to the review of the manuscript. All authors read and approved the final manuscript.

\section{Funding}

The author(s) disclose the following financial support for the research, authorship, and publication of this article: This study and publication was produced with the support of the UNDP/UNFPA/UNICEF/WHO/World Bank Special Training in Human Reproduction, which is the main instrument and leading research agency within the United Nations system concerned with sexual and reproductive health and rights.

\section{Availability of data and materials}

The datasets generated and/or analysed during the current study are not publicly available due the sensitive nature of the data and being qualitative there is a high risk of compromising participant and healthcare system confidentiality but are available from the corresponding author on reasonable request.

\section{Ethics approval and consent to participate}

This study received WHO Ethics Review Committee (ERC) and Research Project Review Panel (RP2) approval. Local country ethics review and approval was provided by the University of the Witwatersrand Human Research Ethics Committee (Health). Further ethics reciprocity was provided by the University of KwaZulu-Natal's Biomedical Research Ethics Committee (BREC). Permission was also obtained from the KwaZulu-Natal Provincial Department of Health to interview healthcare providers. All participants voluntarily signed an informed consent form, which included permission to audio record the interview sessions. Consent for the minors (those aged $<18$ years) to participate in the study was obtained by their identified parents or legal guardians. Assent was obtained from the minors themselves to participate.

Consent for publication

Not applicable.

\section{Competing interests}

The authors declare that they have no competing interests.

\section{Author details}

${ }^{1}$ MatCH Research Unit (Maternal, Adolescent and Child Health Research Unit), Department of Obstetrics and Gynaecology, Faculty of Health Science, University of the Witwatersrand, Durban, South Africa. ${ }^{2}$ School of Public Health and Nursing, College of Health Science, University of KwaZulu-Natal, Durban, South Africa. ${ }^{3}$ Discipline of Pharmaceutical Science, College of Health Science, University of KwaZulu-Natal, Durban, South Africa. ${ }^{4}$ Department of Reproductive Health and Research, World Health Organisation (WHO), Geneva, Switzerland.

Received: 24 April 2018 Accepted: 5 June 2019

Published online: 25 June 2019

References

1. Adding it up: the costs and benefits of investing in sexual and reporductive health 2014 [http://www.unfpa.org/sites/default/files/pub-pdf/ Adding\%20lt\%20Up-Final-11.18.14.pdf].

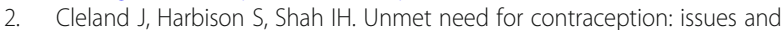
challenges. Stud Fam Plan. 2014;45(2):105-22.

3. SADHS: South African Demographic and Health Survey 2016: Key Indicator Report. In. www.statssa.gov.za: Statistics South Africa; 2016.

4. District Health Barometer 2016/2017. In. Edited by Massyn N, Padarath A, Peer N, Day C. Durban: Health Systems Trust; 2017.

5. SADHS. South African demographic and health survey 1998 - full report. In: Africa MRCS, DHS M, editors. In. Pretoria: National Department of Health; 1998.

6. Maharaj P. Stalling contraception? Perspectives and experiences of sexually active women and men. Agenda. 2012;26(2):100-10.

7. van Rensburg H, Ataguba J, Benatar S, Doherty J, Englebrecht M, Heunis J, Janse van Rensburg A, Kigozi N, McIntyre D, Pelser A et al: Health and health Care in South Africa, second edn. Pretoria: Van Schaik; 2012.

8. Jewkes R, Morrell R. Gender and sexuality: emerging perspectives from the heterosexual epidemic in South Africa and implications for HIV risk and prevention. J Int AIDS Soc. 2010;13(1):6.

9. Adeniyi OV, Ajayi Al, Moyaki MG, Goon DT, Avramovic G, Lambert J. High rate of unplanned pregnancy in the context of integrated family planning and HIV care services in South Africa. BMC Health Serv Res. 2018;18:1-1. 
10. Haffejee F, O'Connor L, Govender N, Reddy P, Sibiya MN, Ghuman S, Ngxongo T, Borg D. Factors associated with unintended pregnancy among women attending a public health facility in KwaZulu-Natal, South Africa. S Afr Fam Pract. 2017:1-5.

11. Morrell $R$, Jewkes $R$, Lindegger $G$. Hegemonic masculinity/masculinities in South Africa: culture, power, and gender politics. Men Masculinities. 2012;15(1):11-30.

12. Schwartz SR, Rees H, Mehta S, Venter WDF, Taha TE, Black V. High incidence of unplanned pregnancy after antiretroviral therapy initiation: findings from a prospective cohort study in South Africa. PLoS One. 2012;7(4):e36039.

13. Iyun V, Brittain K, Phillips TK, le Roux S, Mclntyre JA, Zerbe A, Petro G, Abrams EJ, Myer L. Prevalence and determinants of unplanned pregnancy in HIV-positive and HIV-negative pregnant women in Cape Town, South Africa: a cross-sectional study. BMJ Open. 2018;8(4).

14. Dudgeon MR, Inhorn MC. Men's influences on women's reproductive health: medical anthropological perspectives. Soc Sci Med. 2004;59(7):1379-95.

15. Maharaj P. Male attitudes to family planning in the era of HIV/AIDS: evidence from KwaZulu-Natal, South Africa. J South Afr Stud. 2001;27(2): 245-57

16. Varga CA. The forgotten fifty per cent: a review of sexual and reproductive health research and programs focused on boys and young men in subSaharan Africa. Afr J Reprod Health. 2001:175-95.

17. Helzner JF. Men's involvement in family planning. Reproductive health matters. 1996:4(7):146-54.

18. Sciortino $\mathrm{R}$. The challenge of addressing gender in reproductive health programmes examples from Indonesia. Reproductive health matters. 1998; 6(11):33-44.

19. Cook RJ. International human rights and women's reproductive health. In: Studies in family planning; 1993. p. 73-86.

20. Ndinda C, Ndhlovu T, Khalema NE. Conceptions of contraceptive use in rural KwaZulu-Natal, South Africa: lessons for programming. Int J Environ Res Public Health. 2017;14(4):353

21. Raju S. Negotiating with patriarchy: addressing men in reproductive and child health. Econ Polit Wkly. 2001:4589-92.

22. Preston-Whyte E. Culture, context and behaviour: anthropological perspectives on fertility in southern Africa. Southern African Journal of Demography. 1988:2(1):13-23.

23. Geertz C. The interpretation of cultures. New York: Basic Books Inc. Publishers; 1973

24. Haider $\mathrm{TL}$, Sharma M. Barriers to family planning and contraception uptake in sub-Saharan Africa: a systematic review. International Quarterly of Community Health Education. 2013;33(4):403-13.

25. Bankole A, Singh S. Couples' fertility and contraceptive decision-making in developing countries: hearing the Man's voice. Int Fam Plan Perspect. 1998; 24(1):15-24.

26. Ochako R, Mbondo M, Aloo S, Kaimenyi S, Thompson R, Temmerman M, Kays M. Barriers to modern contraceptive methods uptake among young women in Kenya: a qualitative study. BMC Public Health. 2015;15(1):1-9.

27. Ajah LO, Dim CC, Ezegwui HU, lyoke CA, Ugwu EO. Male partner involvement in female contraceptive choices in Nigeria. J Obstet Gynaecol. 2015;35(6):628-31

28. Kabagenyi A, Jennings L, Reid A, Nalwadda G, Ntozi J, Atuyambe L. Barriers to male involvement in contraceptive uptake and reproductive health services: a qualitative study of men and women's perceptions in two rural districts in Uganda. Reprod Health. 2014;11(1):21.

29. Ochako R, Temmerman M, Mbondo M, Askew I. Determinants of modern contraceptive use among sexually active men in Kenya. Reprod Health. 2017;14(1):56

30. Fennell JL. MEN BRING CONDOMS, WOMEN TAKE PILLS: Men's and Women's roles in contraceptive decision making. Gend Soc. 2011;25(4):496-521.

31. Sternberg P, Hubley J. Evaluating men's involvement as a strategy in sexual and reproductive health promotion. Health Promot Int. 2004;19(3):389-96.

32. Okigbo CC, Speizer IS, Corroon M, Gueye A. Exposure to family planning messages and modern contraceptive use among men in urban Kenya, Nigeria, and Senegal: a cross-sectional study. Reprod Health. 2015;12(1):63.

33. DoH S. National Contraceptive and fertility planning policy and service delivery guidelines. Pretoria: Department of Health N; 2012

34. Ditekemena J, Koole O, Engmann C, Matendo R, Tshefu A, Ryder R, Colebunders R. Determinants of male involvement in maternal and child health services in sub-Saharan Africa: a review. Reprod Health. 2012;9(1):1.

35. Statistics by place [http://www.statssa.gov.za/?page id=1021\&id=ethekwinimunicipality].
36. Pauli J, van Dijk R. Marriage as an end or the end of marriage? Change and continuity in southern African marriages. Anthropology Southern Africa. 2016;39(4):257-66

37. Posel D, Rudwick S, Casale D. Is marriage a dying institution in South Africa? Exploring changes in marriage in the context of ilobolo payments. Agenda. 2011;25(1):102-11.

38. AIDSInfo [http://www.unaids.org/en/dataanalysis/datatools/aidsinfo/].

39. Burr V. Social constructionism. In: Third edn. East Sussex. New York: Routledge; 2015.

40. Lesch E, Kruger L-M. Mothers, daughters and sexual agency in one lowincome south African community. Soc Sci Med. 2005;61(5):1072-82.

41. Aday LA, Andersen RM. A framework for the study of access to medical care. Health Serv Res. 1974, 9(3):208-20.

42. Aday LA, Andersen RM. Equity of access to medical care: a conceptual and empirical overview. Med Care. 1981;19(12):4-27.

43. Andersen RM. Revisiting the Behavioural model and access to medical care: does it matter? In: Journal of Health and Social Behaviour. Vol. 36: American Sociological Association; 1995. p. 1-10.

44. Penchansky R, Thomas JW. The concept of access: definition and relationship to consumer satisfaction. Med Care. 1981;19(2):127-40.

45. Ryan GW, Bernard HR. Techniques to identify themes. Field Methods. 2003; 15(1):85-109.

46. Bruce J. Fundamental elements of the quality of care: a simple framework. Stud Fam Plan. 1990:21(2):61-91.

47. Milford C, Kriel Y, Njau I, Nkole T, Gichangi P, Cordero JP, Smit JA, Steyn PS, Team tUP. Teamwork in qualitative research:descriptions of a multicountry team approach. Int J Qual Methods. 2017;16(1):1609406917727189.

48. Gari S, Doig-Acuna C, Smail T, Malungo JR, Martin-Hilber A, Merten S. Access to HIV/AIDS care: a systematic review of socio-cultural determinants in low and high income countries. BMC Health Serv Res. 2013;13:198.

49. Hunter M. love in the time of AIDS: inequality, gender, and rights in South Africa: Indiana University Press; 2010.

50. Fanslow J. Intimate partner violence and women's reproductive health. Obstetrics, Gynaecology \& Reproductive Medicine. 2017;27(5):148-57.

51. Maharaj P, Cleland J. Women on top: the relative influence of wives and husbands on contraceptive use in KwaZulu-Natal. Women \& Health. 2005; 41(2):31-41

52. Biddlecom AE, Fapohunda BM. Covert contraceptive use: prevalence, motivations, and consequences. Stud Fam Plan. 1998;29(4):360-72.

53. Maharaj P. Promoting male involvement in reproductive health. Agenda: Empowering Women for Gender Equity. 2000;44:37-47.

54. Scorgie F, Kunene B, Smit JA, Manzini N, Chersich MF, Preston-Whyte EM. In search of sexual pleasure and fidelity: vaginal practices in KwaZulu-Natal, South Africa. Culture, health \& sexuality. 2009:11(3):267-83.

55. Higgins JA, Smith NK. The sexual acceptability of contraception: reviewing the literature and building a new concept. J Sex Res. 2016:53(4-5):417-56.

56. Smit J, McFadyen L, Zuma K, Preston-Whyte E. Vaginal wetness: an underestimated problem experienced by progestogen injectable contraceptive users in South Africa. Soc Sci Med. 2002;55(9):1511-22.

57. Beksinska ME, Rees HV. Vaginal discharge: a perceived side effect and minor reason for discontinuation in hormonal injectable users in South Africa. Afr J Reprod Health. 2001:84-8.

58. Dixon-Mueller R. The sexuality connection in reproductive health. Stud Fam Plan. 1993;24(5):269-82.

59. Ngom P. Men's unmet need for family planning: implications for African fertility transitions. Stud Fam Plan. 1997;28(3):192-202.

60. Greenhalgh T. How to read a paper: the basics of evidence based medicine. 4th ed. London: Wiley-Blackwell BMJ Books; 2010.

61. Pope C, Mays N. Qualitative Research in health care. 3rd ed. Massachusetts, Oxford: Victoria: BMJ Publishing; 2006.

62. Ulin PR, Robinson ET, Tolley EE. Qualitative methods in public health: a field guide for applied research., First edn. San Francisco, CA: John Wiley \& Sons; 2012.

63. Sandelowski M. Focus on research methods-whatever happened to qualitative description? Res Nurs Health. 2000;23(4):334-40.

\section{Publisher's Note}

Springer Nature remains neutral with regard to jurisdictional claims in published maps and institutional affiliations. 